\title{
Fine-Needle Aspiration in the Diagnosis of Thyroid Diseases: An Appraisal in Our Institution
}

\author{
Heydar Ali Esmaili and Hassan Taghipour \\ Department of Pathology, Tabriz University of Medical Sciences, Tabriz 51664, Iran \\ Correspondence should be addressed to Hassan Taghipour, taghipourh@yahoo.com \\ Received 13 June 2012; Accepted 2 August 2012 \\ Academic Editors: M. A. Gulcelik, K. K. Khurana, A. Pafiti, and P. Soares
}

Copyright $\odot 2012$ H. A. Esmaili and H. Taghipour. This is an open access article distributed under the Creative Commons Attribution License, which permits unrestricted use, distribution, and reproduction in any medium, provided the original work is properly cited.

\begin{abstract}
Objective and Aims. In the last two decades, fine-needle aspiration cytology (FNAC) of thyroid has been introduced as the most reliable and cost-effective method for diagnosing of clinically important thyroid disorders. The aim of our study was to determine the accuracy and reliability of FNAC in our center. Materials and Methods. Thyroid fine-needle aspiration cytology (FNAC) of 1639 patients from October 2007 to September 2011 was evaluated in our center. Only patients which had a solitary or multiple thyroid nodules were selected for FNA. The FNAC results are classified as benign, malignant, suspicious, and unsatisfactory. From above patients, $192(11.7 \%)$ cases underwent surgery, and histopathologic examination was performed. By comparing the FNAC reports with the corresponding histopathologic results, the accuracy of thyroid FNAC was determined. Results. According to FNAC diagnostic criteria, there were 1054 (64.3\%) benign cases, 128 (7.8\%) malignant, 306 (18.66\%) suspicious and 151 (9.2\%) inadequate for diagnosis. In 192 cases, which underwent surgery, FNAC reports were compared with histopathologic results and statistical indices were calculated. The sensitivity, specificity, and accuracy were $91.6 \%, 100 \%$, and $97 \%$, respectively. These findings strongly support that FNAC as a useful technic for preoperative diagnosis of thyroid lesions. Conclusion. This technique is easy to perform, cost effective, minimally invasive with few complications. FNAC has high sensitivity in diagnosis of thyroid malignancy and also has high diagnostic accuracy in the evaluation of thyroid disorders.
\end{abstract}

\section{Introduction}

During the last two decades, FNAC has emerged as the most reliable and cost-effective method in the diagnosis and management of clinically important thyroid disorders.

Thyroid nodules are very frequent and it is estimated that $4-7 \%$ of adults have palpable enlargement of thyroid and ten times more have impalpable nodules $[1,2]$. Thyroid nodules are more frequent among females, elderly people, history of irradiation to the head and neck, and a diet containing high amount of goitrogenes [1]. Most of the thyroid nodules are benign and fewer than $5 \%$ of them are actually malignant [2-4].

The high frequency of benign versus malignant nodules creates a dilemma; how to manage patients with thyroid nodules that most probably are benign. To overcome this dilemma, thyroid nodules in FNAC are classified as benign, malignant, suspicious, and insufficient for diagnosis. By considering this classification, clinicians will be able to decide if the thyroid nodule should be removed by surgery or not [2]. In fact, introduction of FNAC into the field of thyroid diagnostic tests has reduced thyroid surgeries considerably.

Studies show that $2-15 \%$ of FNAC are insufficient, 50 $70 \%$ benign, $15-30 \%$ suspicious and $5-10 \%$ are malignant [5-8]. Differences in frequency rates are mainly related to study population, aspirators skills, interpreting pathologist's experience, and the difficulty in distinguishing some benign cellular adenomas from their malignant counterparts [9-11].

The aim of our study was to determine the frequency rates of four cytological diagnostic categories and also estimation of FNA accuracy in the diagnosis of thyroid nodules.

\section{Material and Methods}

From October 2007 to September 2011, 1639 patients with single or multiple thyroid nodules diagnosed on physical 
examination and/or sonographic or radioisotopic imaging, underwent fine-needle aspiration with 23-gauage needle and $10-\mathrm{mL}$ syringe. All aspirations were done by one person. For every patient at least three and maximum five separate needles were used, and at least one smear for fixation in 95\% alcohol and one air dried smear from each needle was prepared. Smears were stained by papanicolaous and Giemas methods. Smears with at least twelve follicular cell groups with more than ten preserved follicular cells in each group were considered as sufficient [2].

All of smears were evaluated by one pathologist and FNAC results were classified into 4 groups: benign, suspicious, malignant, and unsatisfactory or insufficient for diagnosis. Smears classified as "benign" included adenomatous (colloid) nodule, Hashimoto's and subacute thyroiditis and other types of thyroiditis. The "suspicious" category included follicular neoplasm, Hurthle cell tumor, and aspirates with atypical features suggestive of, but not diagnostic for malignancy. The smears with cytologic findings of primary or secondary malignancy were classified in the "malignant" category. Smears with insufficient cellularity or poor quality due to delayed or improper fixation and aspirates consisting only cyst fluid were considered "unsatisfactory" or "insufficient for diagnosis" $[1,2]$.

From above patients, $192(11.7 \%)$ cases underwent surgery and histopathologic examination was performed. FNAC reports were compared with the histopathologic results to determine the accuracy of thyroid FNAC. Based on histopathologic confirmation, true positive (TP) and true negative (TN) determined and sensitivity, specificity, PPV and NPV were calculated. The suspicious and inadequate groups were excluded in these calculations, because these groups give no definite information.

\section{Results}

Of the total of 1639 aspirates, 151 (9.2\%) cases were unsatisfactory, the remaining 1488 cases were classified as follows: $1054(64.3 \%)$ benign, 128 (7.8\%) malignant, and $306(18.66 \%)$ suspicious.

Benign lesions included 996 (94.4\%) cases of multinodular goiter, 55 (5.2\%) cases of Hashimoto's and Chronic non-specific lymphocytic thyroiditis, $2(0.2 \%)$ cases of Dequervain's subacute thyroiditis, and one $(0.1 \%)$ case of Riedel's throiditis.

Ninety six (96) cases of benign category underwent surgery due to massive enlargement of thyroid and histopathologic examination was performed. The FNAC reports were confirmed in $92(95.8 \%)$ cases by histopathologic examination, in remaining 4 patients FNAC reports were not confirmed, 3 cases had papillary carcinoma, and one of them had follicular carcinoma in histopathologic examination. Therefore, in benign category, we had 92 true negative and 4 false negative results.

From 128 malignant lesions, papillary carcinoma was diagnosed in $85(66.4 \%)$ cases, follicular carcinoma in 14 (10.9\%), medullary carcinoma in $13(10.1 \%)$, undifferentiated carcinoma in 14 (10.9\%), non-Hodgkin lymphoma with large cells in 1 case $(0.78 \%)$, and finally metastatic carcinoma from kidney was diagnosed in $1(0.78 \%)$ case.

Forty four (44) cases of patients of this category underwent surgery in our center, and the rest of patients did not accept surgery or treated in other centers and some of them had medical contraindications for surgery. On histologic examination, 32 cases were diagnosed papillary carcinoma, 6 cases had follicular carcinoma, 5 cases had medullary carcinoma and one of them was diagnosed as NHL. The cytopathologic diagnoses were confirmed by histopathologic examination in all of 44 cases which underwent surgery. Therefore, we had 44 true positive and 0 false positive in malignant group.

Of the 306 cases with suspicious results, ten cases suspected to have hurtle cell neoplasm, 4 cases suspected to have cystic papillary carcinoma, and the remainder were follicular neoplasms that could not be differentiated from nodular hyperplasia. From this category, 52 patients underwent surgery in our center. For 24 cases, the suspicious were ruled out. The remaining 28 cases included as 23 cases of follicular adenoma, 3 cases of follicular carcinoma, and 2 cases of papillary carcinoma. This group was not included in determining of FNAC accuracy.

Based on the above data, comparing of FNAC results with the corresponding histopathological findings yielded a sensitivity of $91.6 \%$, specificity of $100 \%$, positive predictive value of $100 \%$ and negative predictive value of $95.8 \%$ with diagnostic accuracy of $97 \%$. The results are summarized in Tables 1 and 2 .

\section{Discussion}

As mentioned before, many studies show that $2-15 \%$ of FNAC are unsatisfactory, 50-70\% benign, $15-30 \%$ suspicious, and $5-10 \%$ are malignant.

Our study in 1639 FNACs, showed 9.2\% unsatisfactory, $64.3 \%$ benign, $18.66 \%$ suspicious, and $7.8 \%$ malignant. Our results are in the ranges reported by others.

In our study, 96 cases of benign category underwent surgery and 4 of them had malignancy on histopathologic examination (3 papillary ca. and one follicular ca.). Further evaluations revealed these 4 cases had massive enlargement of thyroid with small foci of malignancy, besides 3 cases of papillary carcinoma were elderly patients with sclerotic pattern. Therefore, false-negative FNAC results occurred in $4(2.08 \%)$ of our cases. This is also consistent with recent reports that suggest a false negative rate of $2 \%$ to $7 \%$ [1214].

The false-negative FNAC results may occur because of sampling error or misinterpretation of cytology. However, it is difficult to estimate the true frequency of false-negative results because only small percentages (about 10\%) of patients with benign cytological findings undergo surgery [11]. Because the false-negative rate for cytologically benign thyroid nodules is as high as $7 \%$, in order to prevent potential miss of malignant lesions, careful clinical followup of these nodules is required. Nodules with benign FNA results can be followed by physical examination and ultrasound $[15,16]$. 
TABLE 1: FNAC results.

\begin{tabular}{lcccc}
\hline Benign & Num & Malignant & Num & suspicious \\
\hline Multi nodular goiter & 996 & Papillary ca. & 85 & Hurtle cell neoplasm \\
Hashimoto and NSLT & 55 & Follicular ca. & 14 & Cystic papillary ca. \\
De quervain thyroiditis & 2 & Medullary ca. & 13 & Follicular neoplasm \\
Reidel thyroiditis & 1 & Other malignancies & 16 & 292 \\
\hline Total & 1054 & & 128 & 306 \\
\hline
\end{tabular}

TABLE 2: FNAC and histopathologic results.

\begin{tabular}{lcccc}
\hline $\begin{array}{l}\text { FNAC } \\
\text { diagnosis }\end{array}$ & $\begin{array}{c}\text { Number of } \\
\text { specimens }\end{array}$ & $\begin{array}{c}\text { Number of patients with } \\
\text { histologic diagnosis }\end{array}$ & Benign (non neoplastic) & Histopathologic diagnosis \\
Malignant & Adenoma \\
\hline Benign & 1054 & 96 & 24 & $4(\mathrm{FN})$ \\
Suspicious* & 306 & 52 & 0 (FP) & 5 \\
Malignant & 128 & 44 & & $44(\mathrm{TP})$ \\
Inadequate & 151 & - & & 0 \\
\hline Total & 1639 & 192 & \\
\hline
\end{tabular}

${ }^{*}$ The suspicious group is not included in determining the statistical indices.

TABLE 3: Distribution of malignant cases among four FNAC categories.

\begin{tabular}{|c|c|c|c|c|c|}
\hline \multirow{2}{*}{ Cytologic diagnosis } & \multicolumn{5}{|c|}{ Histologic typing } \\
\hline & Papillary ca. & Follicular ca. & Medullary ca. & Other malignancy & Total \\
\hline Benign & 3 & 1 & - & - & 4 \\
\hline Suspicious & 2 & 3 & - & - & 5 \\
\hline Malignant & 32 & 6 & 5 & 1 & 44 \\
\hline Inadequate & - & 一 & 一 & 一 & - \\
\hline Total & 37 & 10 & 5 & 1 & 53 \\
\hline
\end{tabular}

One of the important limitations of FNAC is its inability to differentiate follicular hyperplastic nodules and follicular adenomas from well-differentiated follicular carcinoma, which causes a high incidence of "suspicious" category in all studies [17, 18]. Recent studies have demonstrated that the application of molecular-based techniques such as analysis for BRAF and RAS gene mutations and RT-PCR for RET/PTC gene rearrangements is very helpful and improve the differentiation of malignant lesions from their benign counterparts among the patients of "suspicious" category $[19,20]$.

Papillary carcinoma is the most common type in our study, and from 37 histologically confirmed papillary carcinoma, $32(86.48 \%)$ cases had a cytologic diagnosis of malignancy, $2(5.4 \%)$ cases were classified as suspicious, and $3(8.1 \%)$ of them were diagnosed as benign (Table 3 ).

The sensitivity of thyroid FNAC ranges from 65\% to $99 \%$ and its specificity from $72 \%$ to $100 \%$ [21-25]. In our study, the sensitivity and specificity were $91.6 \%$ and $100 \%$, respectively. The statistical indices of FNAC in our study are within the ranges reported by others. The main reason for such a wide range of sensitivity and specificity is how pathologists handle the category of "suspicious" and how they define the false-positive and false-negative results. Some authors include follicular lesion in the malignant/neoplastic category. Others categorize them in the negative group, whereas some exclude them from the calculations [21-25].

There were $151(9.2 \%)$ inadequate cases in our series. Inadequate FNA specimen could be resulted from technical problems, aspiration of sclerotic or calcified nodules, and also nodules with large areas of cystic degeneration or necrosis. The application of ultrasound-guided FNA biopsy improved specimen acquisition and reduced the rate of inadequate specimens, especially in patients with small thyroid nodules [26].

Finally, it is usefull to remind that there are different classification systems for thyroid FNA reporting. Systems range from three to six or more diagnostic categories. The system currently and most commonly used (Bethesda System) contains six categories as follows: benign, lesion (atypia) of undetermined significance, follicular neoplasm, suspicious for malignancy, malignant, and nondiagnostic [27-29]. The classification system used in this article contains four diagnostic categories: benign, suspicious, malignant, and insufficient [2].

\section{Conclusion}

The results of our study and the results reported by similar studies confirm that the FNAC of thyroid is highly 
accurate and has a low rate of false-negative and falsepositive diagnoses. This technique is easy to perform, cost effective, minimally invasive with few complications. FNA helps reduce the cost of care and avoidance of unnecessary surgery in patients with benign lesions, thereby improving the overall quality of life for patients with thyroid nodules.Because of false-negative results, it is important that patients with benign cytologic findings should have close clinical followup.

\section{References}

[1] W. C. faquin, "Aspiration of the thyroid," in Atlas of Diagnostic Cytopathology, B. F. Atkinson, Ed., pp. 460-470, Saunders, 2004.

[2] K. R. Geisin, M. W. Stanley, S. S. Raab, J. F. Silverman, and A. Abati, Modern Cytopathology, Churchill Livingstone, 2004.

[3] J. L. Jameson, "Disorders of the thyroid gland," in Harrison's Principles of Internal Medicine, A. S. Fauci, E. Branunwald, D. L. Kasper et al., Eds., pp. 2224-2247, McGraw-Hill, New York, NY, USA, 17th edition, 2008.

[4] M. J. Yeung and J. W. Serpell, "Management of the solitary thyroid nodule," Oncologist, vol. 13, no. 2, pp. 105-112, 2008.

[5] G. M. Sclabas, G. A. Staerkel, S. E. Shapiro et al., "Fine-needle aspiration of the thyroid and correlation with histopathology in a contemporary series of 240 patients," American Journal of Surgery, vol. 186, no. 6, pp. 702-710, 2003.

[6] J. F. Silverman, R. L. West, and E. W. Larkin, "The role of fine-needle aspiration biopsy in the rapid diagnosis and management of thyroid neoplasm," Cancer, vol. 57, no. 6, pp. 1164-1170, 1986.

[7] M. T. Rojeski and H. Gharib, "Nodular thyroid disease. Evaluation and management," The New England Journal of Medicine, vol. 313, no. 7, pp. 428-436, 1985.

[8] M. A. Charles and K. S. Heller, "Cytologic determinants of well-differentiated thyroid cancer," American Journal of Surgery, vol. 174, no. 5, pp. 545-547, 1997.

[9] J. R. Goellner, H. Gharib, C. S. Grant, and D. A. Johnson, "Fine needle aspiration cytology of the thyroid, 1980 to 1986," Acta Cytologica, vol. 31, no. 5, pp. 587-590, 1987.

[10] G. L. La Rosa, A. Belfiore, D. Giuffrida et al., "Evaluation of the fine needle aspiration biopsy in the preoperative selection of cold thyroid nodules," Cancer, vol. 67, no. 8, pp. 2137-2141, 1991.

[11] H. Gharib and J. R. Goellner, "Fine-needle aspiration biopsy of the thyroid: an appraisal," Annals of Internal Medicine, vol. 118, no. 4, pp. 282-289, 1993.

[12] R. E. Goldstein, J. L. Netterville, B. Burkey, and J. E. Johnson, "Implications of follicular neoplasms, atypia, and lesions suspicious for malignancy diagnosed by fine-needle aspiration of thyroid nodules," Annals of Surgery, vol. 235, no. 5, pp. 656664, 2002.

[13] L. J. Layfield, A. Reichman, K. Bottles, and A. Giuliano, "Clinical determinants for the management of thyroid nodules by fine-needle aspiration cytology," Archives of OtolaryngologyHead and Neck Surgery, vol. 118, no. 7, pp. 717-721, 1992.

[14] Y. Liel, S. Ariad, and M. Barchana, "Long-term follow-up of patients with initially benign thyroid fine-needle aspirations," Thyroid, vol. 11, no. 8, pp. 775-778, 2001.

[15] E. Marqusee, C. B. Benson, M. C. Frates et al., "Usefulness of ultrasonography in the management of nodular thyroid disease," Annals of Internal Medicine, vol. 133, no. 9, pp. 696$700,2000$.

[16] C. Carmeci, R. Brooke Jeffrey, I. R. McDougall, K. W. Nowels, and R. J. Weigel, "Ultrasound-guided fine-needle aspiration biopsy of thyroid masses," Thyroid, vol. 8, no. 4, pp. 283-289, 1998.

[17] G. Altavilla, M. Pascale, and I. Nenci, "Fine needle aspiration cytology of thyroid gland diseases," Acta Cytologica, vol. 34, no. 2, pp. 251-256, 1990.

[18] R. H. Caplan, P. J. Strutt, W. A. Kisken, and S. M. Wester, "Fine needle aspiration biopsy of thyroid nodules," Wisconsin Medical Journal, vol. 90, no. 6, pp. 285-288, 1991.

[19] K. P. Letsas, M. Andrikoula, and A. Tsatsoulis, "Fine needle aspiration biopsy-RT-PCR molecular analysis of thyroid nodules: a useful preoperative diagnostic tool," Minerva Endocrinologica, vol. 31, no. 2, pp. 179-182, 2006.

[20] C. C. Cheung, B. Carydis, S. Ezzat, Y. C. Bedard, and S. L. Asa, "Analysis of ret/PTC gene rearrangements refines the fine needle aspiration diagnosis of thyroid cancer," Journal of Clinical Endocrinology and Metabolism, vol. 86, no. 5, pp. 2187-2190, 2001.

[21] E. L. Mazzaferri, "Management of a solitary thyroid nodule," The New England Journal of Medicine, vol. 328, no. 8, pp. 553559, 1993.

[22] H. Y. Chang, J. D. Lin, J. F. Chen et al., "Correlation of fine needle aspiration cytology and frozen section biopsies in the diagnosis of thyroid nodules," Journal of Clinical Pathology, vol. 50, no. 12, pp. 1005-1009, 1997.

[23] M. Ikram, J. Hyder, S. Muzaffar, and S. H. Hasan, "Fine Needle Aspiration Cytology (FNAC) in the management of thyroid pathology - the Aga Khan University hospital experience," Journal of the Pakistan Medical Association, vol. 49, no. 6, pp. 133-135, 1999.

[24] N. Afroze, N. Kayani, and S. H. Hasan, "Role of fine needle aspiration cytology in the diagnosis of palpable thyroid lesions," Indian Journal of Pathology \& Microbiology, vol. 45, no. 3, pp. 241-246, 2002.

[25] Safirullah, N. Mumtaz, and A. Khan, "Role of fine needle aspiration cytology (FNAC) in the diagnosis of Thyroid swellings," Journal of Postgraduate Medical Institute, vol. 18, no. 2, pp. 196-201, 2004.

[26] L. Leenhardt, G. Hejblum, B. Franc et al., "Indications and limits of ultrasound-guided cytology in the management of nonpalpable thyroid nodules," Journal of Clinical Endocrinology and Metabolism, vol. 84, no. 1, pp. 24-28, 1999.

[27] J. Yang, V. Schnadig, R. Logrono, and P. G. Wasserman, "Fineneedle aspiration of thyroid nodules: a study of 4703 patients with histologic and clinical correlations," Cancer, vol. 111, no. 5, pp. 306-315, 2007.

[28] D. N. Poller, A. K. Ibrahim, M. H. Cummings, J. J. Mikel, D. Boote, and M. Perry, "Fine-needle aspiration of the thyroid," Cancer, vol. 90, 2000.

[29] R. Redman, B. J. Yoder, and N. A. Massoll, "Perceptions of diagnostic terminology and cytopathologic reporting of fineneedle aspiration biopsies of thyroid nodules: a survey of clinicians and pathologists," Thyroid, vol. 16, no. 10, pp. 10031008, 2006. 


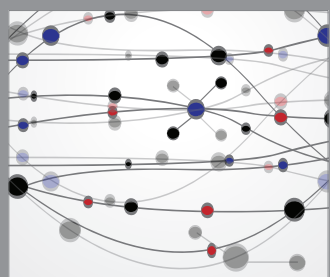

The Scientific World Journal
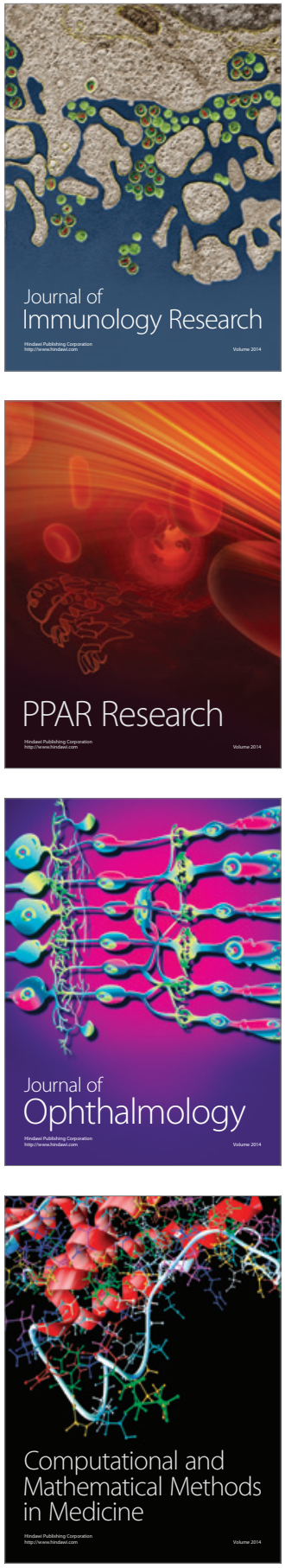

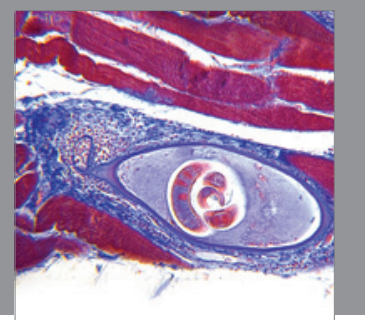

Gastroenterology

Research and Practice
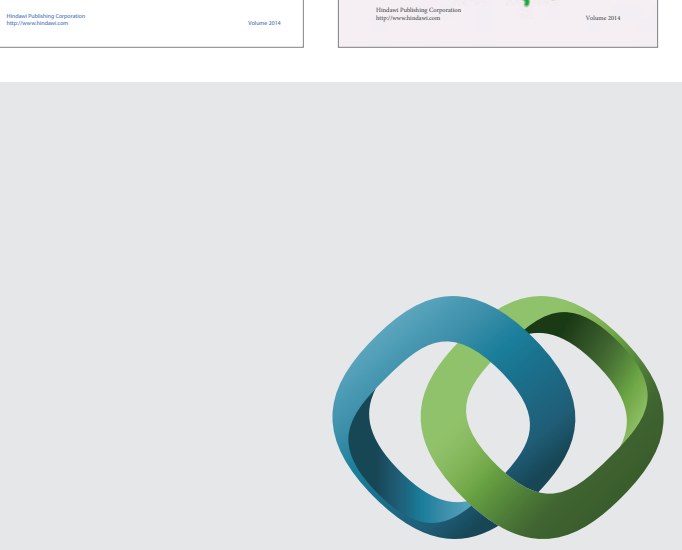

\section{Hindawi}

Submit your manuscripts at

http://www.hindawi.com
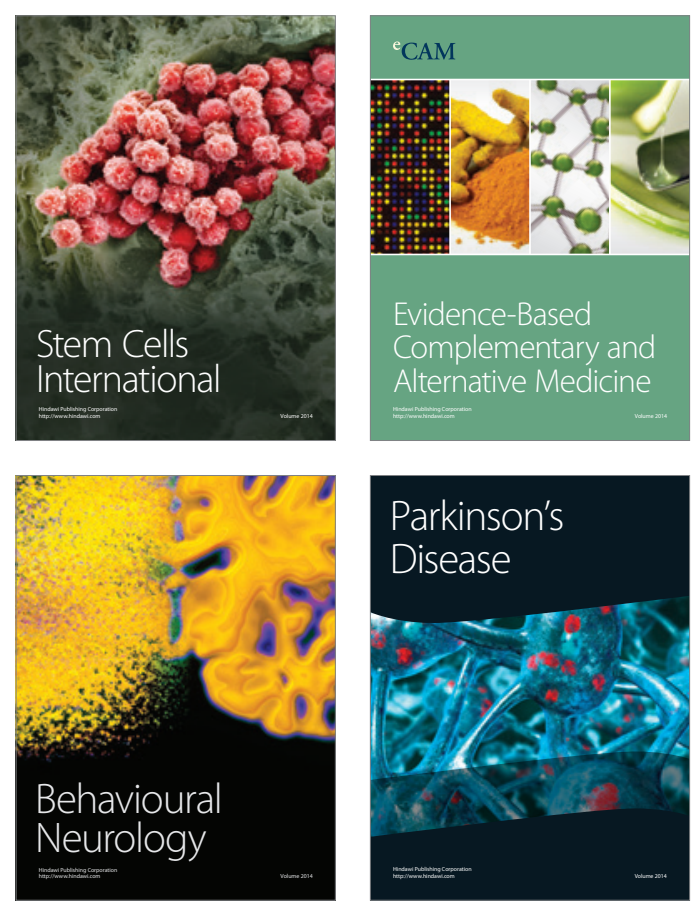

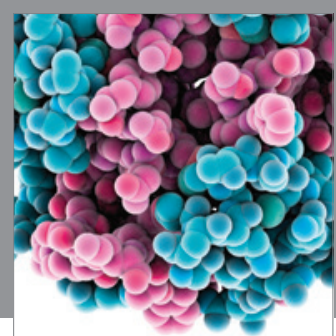

Journal of
Diabetes Research

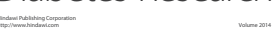

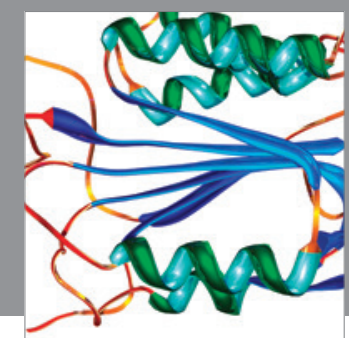

Disease Markers
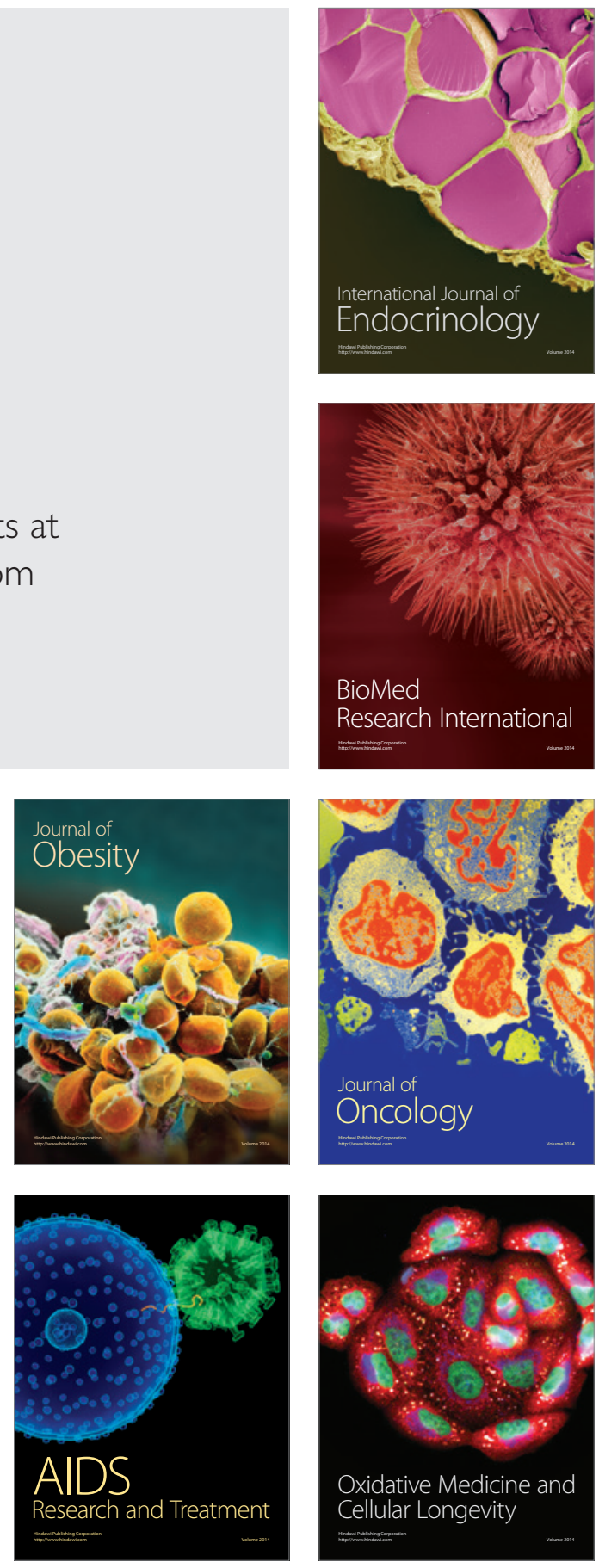